\title{
IMPACT OF CAREGIVER LITERACY ON CHILDREN'S ORAL HEALTH OUTCOMES
}

\author{
by
}

Elizabeth Kelly Miller, DDS

A thesis submitted to the faculty of the University of North Carolina at Chapel Hill in partial fulfillment of the requirements for the degree of Masters of Science in the Department of Pediatric Dentistry in the School of Dentistry.

Chapel Hill

2010

Approved by:

Jessica Y. Lee DDS, MPH, PhD

Darren A. DeWalt, MD, MPH

William F. Vann Jr, DMD, PhD 
(C)2010

Elizabeth Kelly Miller, DDS

ALL RIGHTS RESERVED 


\section{ABSTRACT \\ Impact of Caregiver Literacy on Children's Oral Health Outcomes (Under the direction of Jessica Y. Lee DDS, MPH, PhD)}

Objective: To examine the relationship of primary caregivers' literacy with children's oral health outcomes.

Design: We performed a cross-sectional study of children ages six and younger who presented for an initial dental appointment in the teaching clinics at the University of North Carolina at Chapel Hill School of Dentistry. Caregiver literacy was measured using the Rapid Estimate of Adult Literacy in Dentistry (REALD-30). The outcome measures included oral health knowledge, oral health behaviors, primary caregiver's reports of their child's oral health status, and the clinical oral health status of the child as determined by a clinical exam completed by trained, calibrated examiners.

Results: Among the 106 caregiver/child dyads enrolled, 59\% of the children were male, 52\% were white, and 86\% caregivers were the biological mothers. The bivariate results showed no significant relationships between literacy and oral health knowledge $(\mathrm{p}=0.16)$ and behaviors $(\mathrm{p}=0.24)$; however, there was an association between literacy and oral health status $(\mathrm{p}<0.05)$. The multivariate analysis controlled for race, and income; this analysis revealed a significant relationship between caregiver literacy scores and clinical oral health status as determined using a standardized clinical exam. Caregivers of children with mild to moderate treatment needs were more likely to have higher REALD-30 scores than those with severe treatment needs $(\mathrm{OR}=1.14 ; 95 \% \mathrm{CI} 1.05: 1.25, \mathrm{p}=0.003)$.

Conclusions: Caregiver literacy is significantly associated with children's dental disease status. 


\section{ACKNOWLEDGEMENTS}

To my thesis advisor, Dr. Jessica Y. Lee, for her unconditional support, friendship and mentorship. Having Dr. Lee as a teacher and research mentor has been among the most rewarding of my educational experiences and I thank her for being inspiring, never intimidating and, at the same time, expecting the highest standards from me. She embraces a teaching philosophy involving mutual respect and encourages me to have confidence in my knowledge, whether it is a clinical skill, an academic concept, or a research finding. I will be forever grateful for the opportunity to have had Dr. Lee as my thesis advisor.

To committee member, Dr. William F. Vann, Jr., for his unwavering support, friendship, and mentorship. I attribute much of my strong educational foundation to Dr. Vann's effort and influence. I wouldn't be where I am today without his guidance. I feel privileged to have been a student of his over the years and thank him for instilling in me a strong and burning desire to continue to learn as much as possible. Many of my treatment decisions in the future will be based off of the question, "What would Dr. Vann do?"

To committee member, Dr. Darren A. DeWalt, for his support and guidance. His knowledge about health literacy has been invaluable and I thank him for his insight into the design of the project, his suggestions with data analysis and his help in writing my thesis.

To Hilary Kelly and Diane Baker for their help with patient recruitment and interviews.

To Stephanie Jackson and Jossein Shahangian for their help with clinical exams.

To my fellow pediatric dental residents for their moral support and friendship. 


\section{TABLE OF CONTENTS}

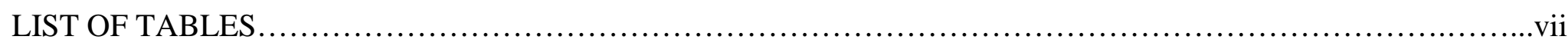

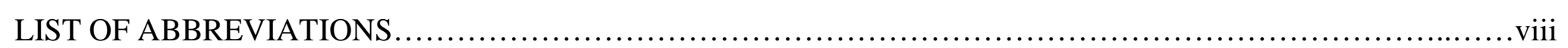

\section{Chapter}

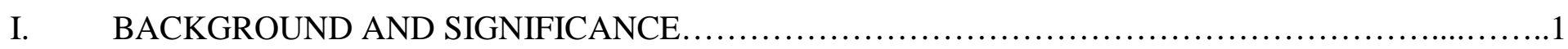

The Importance of Children's Oral Health................................................................

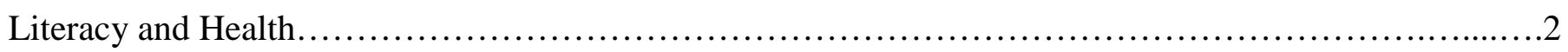

Caregivers' Literacy Impacts Children's Oral Health............................................

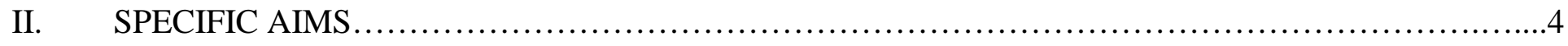

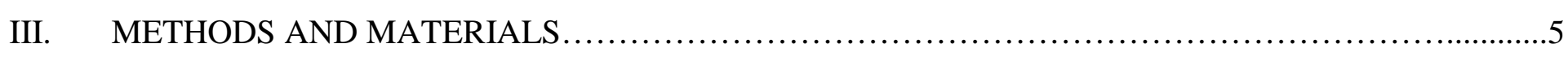

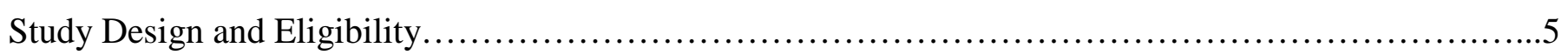

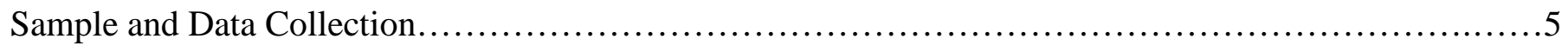

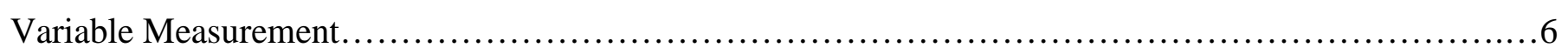

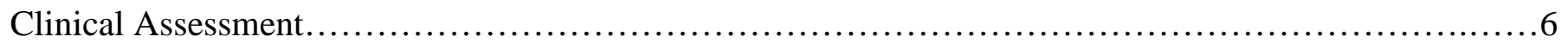

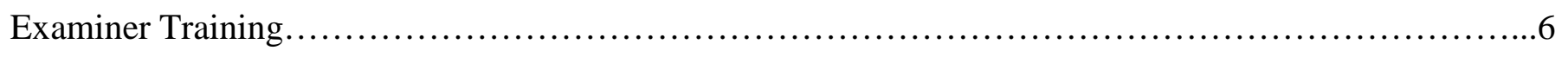

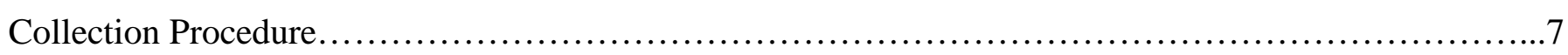

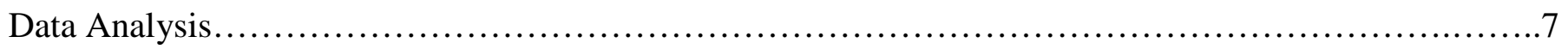

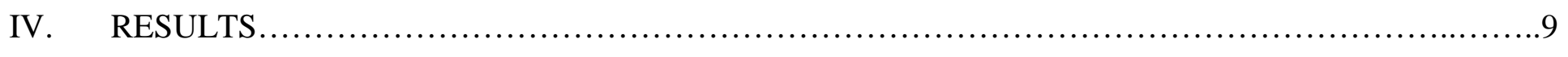

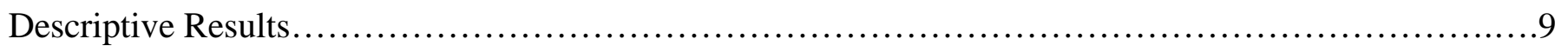

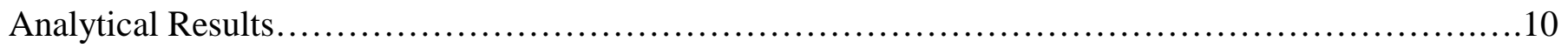




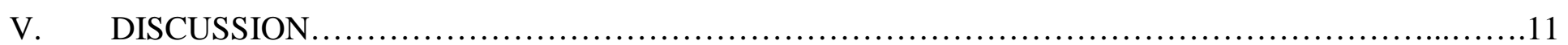

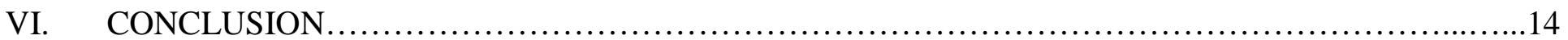

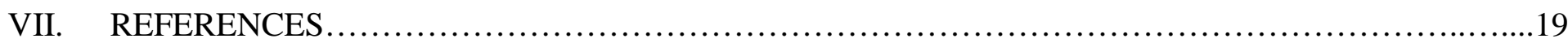




\section{LIST OF TABLES}

Table

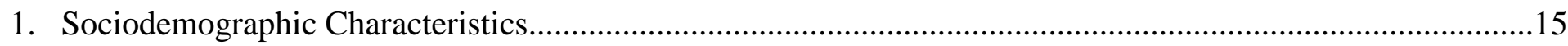

2. Bivariate Relationships for Literacy and Oral Health Knowledge..........................................16

3. Bivariate Relationships for Literacy and Oral Health Behaviors and Dental Use ..........................17

4. Logistic Regression Models Predicting Oral Health Status.................................................18 


\section{LIST OF ABBREVIATIONS}

REALD-30: Rapid Estimate of Adult Literacy in Dentistry

NAAL: National Assessment of Adult Literacy

NHANES III: National Health and Nutrition Examination Survey 


\section{BACKGROUND AND SIGNIFICANCE}

\section{The Importance of Children's Oral Health}

Dental caries is the most common chronic disease of children ages 5-17 and is five times more common than asthma. ${ }^{1}$ Although oral health in the United States (US) has improved significantly since the 1960 s, $^{2}$ preventable and untreated oral diseases remain widespread, particularly among children of low-income and minority status. The General Accounting Office has reported that poor children have five times more untreated caries than children from higher income families. ${ }^{2}$ Untreated dental caries in children can lead to problems with eating, speaking, attending school, learning, and general health. ${ }^{1}$

Many reasons explain why preventable oral diseases remain widespread in children and why caregivers may not adopt preventive practices that are effective in maintaining oral health. ${ }^{3}$ Finances and access are major reasons but other reasons are plausible. We hypothesized that caregiver literacy may be an important explanatory variable in oral health behavior and the development of dental caries among children. Caregiver literacy is related to other health outcomes among young children ${ }^{4,5}$ and may represent a mutable factor for overcoming dental health disparities. In this study, we investigated the relationship between caregiver's literacy and their child's oral health.

\section{$\underline{\text { Literacy and Health }}$}

Literacy skills are associated with general health and intersect with other health determinants in a myriad of ways. ${ }^{3}$ According to the most recent National Assessment of Adult Literacy (NAAL) Survey, almost half (43\%) of US adults are unable to accurately and consistently use available print materials for everyday activities such as those related to health and safety, finance, or civic engagement. ${ }^{6,7}$ Similarly, in a nationally representative study, Yin et al. found that $28 \%$ of parents had below basic/basic health literacy and greater than $2 / 3$ were unable to correctly enter demographic information on health insurance forms. ${ }^{8}$ This disturbing trend in poor literacy is not improving; in fact, 
the total number of adults with inadequate literacy skills to function in the US increases by approximately 2.25 million persons annually. ${ }^{9}$

The most recent NAAL was the first to measure health literacy of US adults, finding that both literacy and health literacy are highly correlated. ${ }^{6}$ Literacy is defined as "the degree to which individuals have the capacity to obtain, process, understand and act on (health) information and services needed to make appropriate (health) decisions."10 Because of difficulty reading, processing, and acting upon the types of health information encountered in everyday life, approximately 77 million Americans may struggle in our current health-care system. ${ }^{6,11}$ Growing evidence of the importance of literacy in health outcomes has led a variety of professional and governmental organizations to prioritize interventions that improve health and health care for people with inadequate literacy skills. ${ }^{12-15}$ Indeed, efforts to address health literacy have emerged as a major goal of the research agenda of health professionals, policy makers, and advocates, as well as for the goals for Healthy People $2010 .^{10}$

\section{$\underline{\text { Caregivers' Literacy Impacts Children's Health }}$}

Individuals with low literacy skills often have poorer health knowledge and health status, unhealthy behaviors, less utilization of preventive services, higher rates of hospitalizations, higher rates of chronic diseases, increased health care costs, and ultimately poorer health outcomes than those with higher literacy levels. ${ }^{15-18}$

Although most published literacy studies have assessed adult health outcomes, there is a growing body of evidence that has examined the implications of low caregivers' literacy for children's health. ${ }^{19}$ Because children are dependent on their caregiver for access to health care, ${ }^{20}$ low adult literacy has potential detrimental implications for the pediatric population. In the mid-1990s, a series of studies linked low literacy to patient health behaviors with several studies suggesting associations between maternal literacy skills and health behaviors important for infant health such as smoking, immunizations, initiation of breastfeeding, and adherence to medical treatment. ${ }^{21,22}$

Two recent investigations measured parental literacy and pediatric health outcomes. The first found that glycemic control was directly related to the literacy of the parent. ${ }^{4}$ The second demonstrated that parents with low 
literacy had less asthma-related knowledge and their children were more likely to have moderate or severe persistent asthma, greater use of rescue medications, increased incidence of emergency department visits and hospitalizations. $^{5}$ 


\section{SPECIFIC AIMS}

The specific aims of this investigation were to examine the relationship between caregiver literacy and four oral health outcomes: oral health knowledge, oral health behaviors, primary caregivers' reports of their child's oral health status, and the clinical oral health status of the child as determined by disease severity. 


\section{METHODS AND MATERIALS}

\section{$\underline{\text { Study Design and Eligibility }}$}

This was a cross-sectional study to assess the relationship of the primary caregiver's literacy and the child's oral health outcomes. The study was approved by the Biomedical Institutional Review Board at the University of North Carolina at Chapel Hill. Eligibility criteria included healthy children ages $\leq 6$ years, who were accompanied by the primary caregiver. This age group was chosen for a couple of reasons: 1) the preschool aged population's oral health is most influenced by their caregivers and 2) the caries severity index used in our study has been validated on this age group. The instrument used to measure literacy has been validated in English only, so only children with English-speaking caregivers were eligible.

\section{$\underline{\text { Sample and Data Collection }}$}

A convenience sample of caregiver/child dyads was recruited from children presenting for an initial dental appointment to the UNC School of Dentistry teaching clinic. The initial appointment was defined as an emergency visit or a new patient examination.

After obtaining written informed consent for study participation, eligible caregivers were asked to complete inperson, verbally-administered surveys by trained interviewers in a private area. To allow for review of patient records for analysis of children's oral health status, a HIPPA waiver was obtained. If the primary caregiver experienced any difficulty reading the consent or HIPPA waiver forms, the interviewer read them aloud. All survey data were collected prior to contact with a dental provider. After introduction to the examining dentist, the child underwent a comprehensive dental examination and clinical charting. To avoid the introduction of bias, the interviewer always differed from the clinical examiner, both of whom were blinded. After the completion of the examination, an incentive ( $\$ 10.00$ gift card) was given to the caregiver/child. 


\section{$\underline{\text { Variable Measurement }}$}

We measured caregiver literacy using the Rapid Estimate of Adult Literacy in Dentistry (REALD-30). ${ }^{18}$ This previously validated instrument includes 30 words arranged in order of increasing difficulty. ${ }^{18}$ The Cronbach's alpha for REALM was 0.87 . The convergent validity to REALM and TOFHLA were 0.86 and 0.64 , respectively. Using the REALD-30, the words are read aloud by the caregiver to the interviewers. Because REALD-30 is a word recognition test, subjects were asked not to try and pronounce the words, but rather skip them if they did not know the word. To score the REALD-30, one point is given to each word pronounced correctly and then summed to get an overall score. The total score has a possible range of 0 (lowest literacy) to 30 (highest literacy).

In addition to the REALD-30, each caregiver completed surveys to examine socio-demographic status, the caregiver's oral health knowledge, the child's oral health behavior, the caregiver's perceptions of oral health status, and potential barriers to oral health. The survey questions were derived from previously developed and tested questionnaires used in pediatric oral health research (Appendix 1). ${ }^{23-25}$

\section{Clinical Assessment}

We measured the clinical dental health status based on severity using a severity index described originally by Poulson \& Horowitz ${ }^{26}$ as adapted by Wong and colleagues ${ }^{27}$. Our child patients were assigned by calibrated dental examiners to one of three severity zones: 1) caries-free and no treatment needs, 2) low-moderate treatment needs defined as visible occlusal and interproximal carious lesions), or 3) advanced treatment needs defined as visible anterior carious lesions.

\section{Examiner Training}

The clinical examiners were trained and calibrated in interview and survey methods in two training sessions focused on establishing examiner reliability using the severity zone index. Later, the examiners were tested using 20 patient cases to determine inter-examiner reliability. The first session took place prior to data collection and the second session took place approximately half-way through data collection. 


\section{Collection Procedures}

The surveys were verbally administered by two trained interviewers who relied upon a standardized order of data collection as follows: the survey of the caregiver's oral health knowledge, the survey of the child's oral health behavior, the survey of the caregiver's perception of oral health status and the caregiver's literacy instrument. Reliance on this sequence prevented confounding of oral health knowledge, based on the behavior questions. Measuring literacy can be a sensitive for individuals who are unable to pronounce the words correctly; therefore, the REALD-30 was administered last.

\section{$\underline{\text { Data Analysis }}$}

All data were entered into Microsoft Access with double-entry and tested for accuracy with SAS statistical analysis software (SAS Corporation, Cary, NC). Best sample size estimations were calculated using previous published prevalence data on literacy ${ }^{18}$ and the dental health severity index. ${ }^{27}$ The computed sample size requirements for $\alpha=0.05$ (two-sided) and the power of $0.90^{28}$ was 81 subjects. Our goal for this study was to recruit a minimum of a 100 subjects to provide adequate power for our dental health severity index. Sample size estimates for the knowledge and behaviors outcome measures could not be determined because there was no published prevalence data.

Descriptive statistics reporting percentage frequency distributions of responses for caregiver socio-demographics, oral health behaviors, and knowledge were run using STATA statistical software (College Station, TX, 2009). After an examination of bivariate associations of independent variables and our four outcomes measures, regression models were developed to test the relationship of literacy on child health outcomes, while accounting for control variables. We considered four child health outcomes: (1) caregivers' oral health knowledge as measured by an 11-item knowledge scale, ${ }^{23}$ a linear measure scored in the range of 1-11, (2) oral health behaviors as defined by Douglass and colleagues, ${ }^{24}$ (3) dental health status of the child as reported by the caregiver using a 5 point Likert-type scale measure using a question taken from the NHANES III survey, ${ }^{25}$ and (4) children's dental health status as measured by the severity index (none/mild/moderate versus severe). 


\section{RESULTS}

\section{Descriptive Results}

Among the 106 caregiver/child dyads recruited for the study (Table 1), slightly more than half $(59.4 \%)$ of the children were male and slightly more than half $(52.8 \%)$ were white. The age range of the children recruited was as follows: $8 \%$ were one, $25 \%$ were two, $18 \%$ were three, $18 \%$ were four, $19 \%$ were five, and $12 \%$ were six. The majority (59.1\%) of the children had dental insurance with most (73.7\%) covered by Medicaid or the State Child Health Insurance Programs.

Most caregivers were knowledgeable about basic oral hygiene and dietary recommendations (Table 2). They demonstrated a high knowledge (93.3\%) of the concept that fluoride helps prevent tooth decay. A total knowledge score was created as a sum of the correct items on Table 2. The average total knowledge score was 7.5 items (SD 1.6) correct of the 11 items asked.

Results from behavior survey items (Table 3) revealed nighttime bottle feeding was common as almost half (42.6\%) of the caregivers reported a current or past history of putting their child to bed with something other than water. To understand challenges in managing children's oral health, we asked our caregivers to report potential barriers. The majority of them cited the child's behavior (39.6\%) as the major barrier, followed by a lack of time (23.7\%).

More than half $(56.7 \%)$ of the caregivers reported that their children's dental health status was excellent, very good, or good with 9\% reporting that their children's dental health status was excellent, $14 \%$ very good, and 34\% good. $20 \%$ reported their children's dental health status as fair, $22 \%$ as poor and $1 \%$ didn't know.From the clinical exam, almost two-thirds of the children (64.4\%) were caries free and had no or minimal dental treatment needs with $44 \%$ of the children caries free with no needs, $20 \%$ with minimal or moderate needs and $36 \%$ with advanced needs.Our clinical examiners were in very high agreement with inter-examiner reliability scores of $95 \%$ and $98 \%$ at each of the respective 
calibration sessions. The mean literacy score (REALD-30) was 20.7 (SD \pm 5.5 ; range 5-30). More than half (55.7\%) had limited literacy, as defined by a score of 22 or less.

\section{$\underline{\text { Analytic Results }}$}

In our bivariate analyses literacy was significantly associated with several knowledge items (Table 2), such as understanding that the risk of tooth decay increases with more frequent sugar exposure $(\mathrm{P}=0.04)$ and that a child's overall health is dependent on whether they have cavities $(\mathrm{P}<0.001)$. There was no significant relationship between REALD-30 scores and overall oral health knowledge score (Spearman Rho 0.13, p=0.16).

Although our analytical findings indicated that there were no significant relationships between literacy and oral health behaviors (Table 3), we did find an association with oral health status. Children with reported excellent/very good/good oral health status had a mean REALD-30 score of 22 while those that reported to have poor/fair oral health status had a mean REALD-30 score of 19. Similarly, those children who had severe disease as measured by a clinical exam had a mean REALD-30 score of $18(\mathrm{P}=0.003)$ compared to those that had no or minimal needs having a mean REALD-30 score of $22(\mathrm{P}=0.001)$. Both differences were significant.

The results of the multivariate logistic regression models that controlled for race (white versus other), and income (less than 30,000 versus greater than 30,000) are illustrated on Table 4. Caregivers of children with mild to moderate treatment needs were more likely to have higher REALD-30 scores than those with severe treatment needs $(\mathrm{OR}=1.14$; 95\% CI 1.05:1.25; the OR represents the increase in odds of good dental health for each point increase on caregiver REALD score). Multivariate models examining the relationships between literacy and proxy-reported oral health status measures (excellent/very good/good versus fair/poor) revealed no significant relationship (OR=1.08; 95\% CI 0.99:1.17). 


\section{DISCUSSION}

In this investigation we hypothesized that caregivers are responsible for ensuring self-management behaviors for young children and that caregiver literacy would be related to oral health knowledge, behavior, and health outcomes. Our results indicated that low caregiver literacy was associated with poorer child dental health status. This relationship was sustained even after adjustment for race and income as potential confounding variables. Even with this significant finding, the process by which low literacy leads to poor oral health status is unclear.

Our findings are consistent with other results found in the clinical literature. Some studies have found no relationship between caregiver literacy and important outcomes or knowledge ${ }^{29,30}$ while other researchers have found that caregiver literacy is related to other important health outcomes. ${ }^{4,5}$ As this area of research emerges, it appears that the pathways between caregiver literacy and child health may be complex. ${ }^{19}$

Literacy was not associated with our proposed mediating variables, dental health knowledge and dental health behaviors. This was a surprising finding because many studies of literacy and health knowledge demonstrate a relationship. ${ }^{29}$ There are a few reasons that may explain this lack of significant finding. One explanation may be that the caregivers generally had good knowledge. Another is that our knowledge instrument may not have been sufficiently discriminating. Our instrument was constructed to represent important facets of child oral health that are relevant for behavior. It is also possible that oral health knowledge is not as important as actual oral health behavior in predicting outcomes; however, we did find significant associations with several single knowledge items such as sugar exposure, use of fluoride, systemic health implications of oral health, and professional dental visit guidelines. Lastly, we also did not find a relationship between literacy and behavior. This could be a true association, or it could be biased by socially desirable responding in the context of the questionnaire we used in the clinical setting. A more thorough evaluation of oral health behaviors may be needed to understand the association between caregiver literacy and child health outcomes. 
The results should be considered in light of the study's limitations. Firstly, the study used a cross-sectional design and therefore could provide differing results if another time-frame had been chosen. This also makes it difficult to establish causality. Secondly, the data were collected from a convenience sample of study subjects from the dental clinics, so the sample represents families who were seeking dental care. Such families may be different from those who have not sought dental care for their children and the former may value dental care higher and/or be more informed about oral health. Finally, the REALD-30 instrument has been validated in English only so our recruitment was limited to Englishspeaking patients.

Despite these limitations, we believe this study has several strengths. Firstly, calibrated examiners were used to interview caregivers as well as perform the clinical exam. Secondly, a clinical examination was used as our outcome measure. This was significant because this is the first study to examine dental disease severity by clinical examination. All other reported studies have examined disease severity using parental oral health status reports or chart reviews. Lastly, we used a validated instrument to measure dental literacy. Previous studies examining dental literacy used general reading ability measures or education attainment as a proxy measures.

This study is the first to examine the role of caregiver literacy on oral health outcomes. There are several significant implications of our findings. Our results suggest that caregiver literacy is related to children's oral health status; as such, interventions to improve children's oral health status may be more successful if they are developed and implemented with an understanding of caregiver literacy. Appropriate communication techniques that take into consideration caregiver literacy may be needed in delivering more effective anticipatory guidance messages to caregivers of young children.

Until recently, caregiver literacy has received little attention in oral health. Because children are dependent on their caregiver for access to health care, low caregiver literacy has potential detrimental implications for the pediatric population. Previous research has suggested that adult health knowledge and health behaviors have a significant impact on pediatric health outcomes. Our findings also have important implications for public health and provide much needed 
information to target wider interventions on a community level. Many community-based preventive programs for young children target caregivers with educational messages. Understanding caregiver literacy when developing these messages may increase their effectiveness. 


\section{CONCLUSIONS}

Caregiver literacy was significantly associated with children's oral health outcomes using a clinical dental examination. These results point to goals for future studies by providing a framework necessary to design targeted interventions of oral health knowledge, behaviors, and literacy. Such strategies have great potential to improve caregiverprovider communication, provide more effective caregiver oral health education and anticipatory guidance and, ultimately, improve children's oral health. 
Table 1. Sociodemographic Characteristics

\section{Child's Sex \\ Male \\ Female}

\section{Child's Race}

White

Black/African American

Hispanic/Latina

Other

Child Having Dental Insurance

Yes

No

Type of Dental Insurance

Medicaid/Health Choice

Private

Caregiver Relationship

Mother

Father

Grandfather

Other

Caregiver Education Level

Less than High School

High School or GED

Some College or Technical Degree

College Degree or More

\section{Marital Status}

Married

Separated/Divorced

Never Married or Single

Other

Household Income

$\$ 30,000$ or less

$\$ 30,000-50,000$

More than $\$ 50,000$

\begin{tabular}{cc}
$\begin{array}{c}\text { Frequency } \\
\text { (N) }\end{array}$ & $\begin{array}{c}\text { Percent } \\
\text { (\%) }\end{array}$ \\
\hline 63 & 59.4 \\
43 & 40.6
\end{tabular}

$24 \quad 22.6$

$11 \quad 10.4$

$15 \quad 14.2$


Table 2: Bivariate Relationships for Literacy and Oral Health Knowledge

(Correct responses are indicated by $*$ )

\begin{tabular}{|c|c|c|c|}
\hline Variable & \% Response & $\begin{array}{l}\text { Mean Literacy } \\
\text { Scores } \\
\text { (REALD-30) }\end{array}$ & P-value \\
\hline $\begin{array}{l}\text { Drinking juice from a "sippy" cup throughout the } \\
\text { day can cause cavities } \\
\text { Agree* } \\
\text { Disagree/Don't know }\end{array}$ & $\begin{array}{l}73.3 \\
26.7 \\
\end{array}$ & $\begin{array}{l}20.7 \\
20.4 \\
\end{array}$ & 0.72 \\
\hline $\begin{array}{l}\text { Parents with cavities can transmit germs that cause } \\
\text { tooth decay to their children } \\
\text { Agree* } \\
\text { Disagree/Don't know } \\
\end{array}$ & $\begin{array}{l}23.8 \\
76.2 \\
\end{array}$ & $\begin{array}{l}21.1 \\
19.2 \\
\end{array}$ & 0.12 \\
\hline $\begin{array}{l}\text { The risk of getting tooth decay increases with more } \\
\text { frequent exposure to sugar in snacks } \\
\text { Agree* } \\
\text { Disagree/Don't know }\end{array}$ & $\begin{array}{c}96.1 \\
3.9\end{array}$ & $\begin{array}{l}20.9 \\
15.3\end{array}$ & 0.04 \\
\hline $\begin{array}{l}\text { Fluoride helps prevent tooth decay } \\
\text { Agree* } \\
\text { Disagree/Don't know }\end{array}$ & $\begin{array}{c}93.3 \\
6.7\end{array}$ & $\begin{array}{l}20.8 \\
18.6\end{array}$ & 0.29 \\
\hline $\begin{array}{l}\text { All children older than } 6 \text { months should receive } \\
\text { fluoride drops or tablets every day } \\
\text { Agree/Don't know } \\
\text { Disagree* }\end{array}$ & $\begin{array}{l}67.0 \\
33.0 \\
\end{array}$ & $\begin{array}{r}19.9 \\
22.4 \\
\end{array}$ & 0.03 \\
\hline $\begin{array}{l}\text { Parents should start cleaning their child's teeth as } \\
\text { soon as the first baby tooth comes in } \\
\text { Agree* } \\
\text { Disagree/Don't know } \\
\end{array}$ & $\begin{array}{l}87.6 \\
12.4 \\
\end{array}$ & $\begin{array}{l}20.7 \\
20.6 \\
\end{array}$ & 0.94 \\
\hline $\begin{array}{l}\text { Parents should brush their child's teeth twice a day } \\
\text { until the child can handle the toothbrush alone } \\
\text { Agree* } \\
\text { Disagree/Don't know }\end{array}$ & $\begin{array}{c}97.1 \\
2.9\end{array}$ & $\begin{array}{l}20.8 \\
19.6\end{array}$ & 0.71 \\
\hline $\begin{array}{l}\text { A child's overall health does not depend on whether } \\
\text { he/she has cavities in baby teeth } \\
\text { Agree/Don't know } \\
\text { Disagree* }\end{array}$ & $\begin{array}{l}47.7 \\
52.3 \\
\end{array}$ & $\begin{array}{l}18.8 \\
22.4 \\
\end{array}$ & $<0.001$ \\
\hline $\begin{array}{l}\text { A cavity in a baby tooth should be filled only when } \\
\text { it hurts } \\
\text { Agree/Don't know } \\
\text { Disagree* }\end{array}$ & $\begin{array}{l}27.7 \\
72.3 \\
\end{array}$ & $\begin{array}{l}19.0 \\
21.2 \\
\end{array}$ & 0.03 \\
\hline $\begin{array}{l}\text { All children should be checked by a dentist around } \\
\text { the time the first baby tooth comes in } \\
\text { Agree* } \\
\text { Disagree/Don't know }\end{array}$ & $\begin{array}{r}53.3 \\
46.7 \\
\end{array}$ & $\begin{array}{l}19.5 \\
21.9 \\
\end{array}$ & 0.02 \\
\hline $\begin{array}{l}\text { Tooth decay in baby teeth can cause infections that } \\
\text { can spread to the face and other parts of the body } \\
\text { Agree* } \\
\text { Disagree/Don't know }\end{array}$ & $\begin{array}{l}62.9 \\
37.1 \\
\end{array}$ & $\begin{array}{l}21.1 \\
19.4 \\
\end{array}$ & 0.30 \\
\hline
\end{tabular}


Table 3: Bivariate Relationships for Literacy and Oral Health Behaviors and Dental Use

\begin{tabular}{|c|c|c|c|}
\hline Variable & $\%$ Response & $\begin{array}{l}\text { Mean Literacy } \\
\text { Scores } \\
\text { (REALD-30) }\end{array}$ & P-value \\
\hline Behaviors Measures & & & \\
\hline $\begin{array}{l}\text { Child to bed with anything other than water } \\
\text { Always/Sometimes } \\
\text { Never }\end{array}$ & $\begin{array}{l}42.6 \\
57.4\end{array}$ & $\begin{array}{l}19.6 \\
21.5\end{array}$ & 0.08 \\
\hline $\begin{array}{l}\text { Brush or clean your child's teeth or gums every day } \\
\text { Yes } \\
\text { No }\end{array}$ & $\begin{array}{l}84.9 \\
15.1\end{array}$ & $\begin{array}{l}20.7 \\
20.4\end{array}$ & 0.82 \\
\hline $\begin{array}{l}\text { Use toothpaste when brushing your child's teeth } \\
\text { Yes } \\
\text { No }\end{array}$ & $\begin{array}{c}98.1 \\
1.9\end{array}$ & $\begin{array}{l}23.0 \\
20.6\end{array}$ & 0.55 \\
\hline Dental Use Measures & & & \\
\hline $\begin{array}{l}\text { Child has previously visited the dentist } \\
\text { Yes } \\
\text { No }\end{array}$ & $\begin{array}{l}66.9 \\
33.1\end{array}$ & $\begin{array}{l}19.6 \\
22.9\end{array}$ & 0.03 \\
\hline $\begin{array}{l}\text { Other children have visited the dentist } \\
\text { Yes } \\
\text { No }\end{array}$ & $\begin{array}{l}78.4 \\
21.6\end{array}$ & $\begin{array}{l}21.2 \\
19.6\end{array}$ & 0.29 \\
\hline
\end{tabular}


Table 4. Logistic Regression Models Predicting Oral Health Status

\begin{tabular}{|c|c|c|c|c|c|c|}
\hline \multirow[b]{2}{*}{ Variable } & \multicolumn{3}{|c|}{$\begin{array}{l}\text { Disease Severity (Clinical Exam) } \\
\text { None/Mild/Mod vs Severe }\end{array}$} & \multicolumn{3}{|c|}{$\begin{array}{l}\text { Reported Oral Health Status } \\
\text { Ex//VG/Good vs Fair/Poor }\end{array}$} \\
\hline & OR & $95 \% \mathrm{CI}$ & P-value & OR & $95 \% \mathrm{CI}$ & P-value \\
\hline $\begin{array}{l}\text { REALD-30 } \\
\text { Linear } \\
0-30 \text { Scale }\end{array}$ & 1.14 & $1.05 ; 1.25$ & 0.003 & 1.08 & $0.99 ; 1.17$ & 0.07 \\
\hline $\begin{array}{l}\text { Race } \\
\text { White vs } \\
\text { Non White/Minority } \\
\text { (Reference) }\end{array}$ & 0.72 & $0.28 ; 1.85$ & 0.52 & 0.88 & $0.37 ; 2.09$ & 0.77 \\
\hline $\begin{array}{l}\text { Income } \\
\text { Less than } \$ 30,000 \text { vs } \\
>=\$ 30,000 \text { year } \\
\text { (Reference) }\end{array}$ & 0.67 & $0.25 ; 1.77$ & 0.59 & 0.46 & $0.19 ; 1.13$ & 0.09 \\
\hline
\end{tabular}

$(\mathrm{n}=102)$

*Significant at $\mathrm{P}<0.05$ 


\section{REFERENCES}

1. Centers for Disease Control. Preventing dental caries. Available at: http://www.cdc.gov.libproxy.lib.unc.edu/nccdphp/publications/factsheets/Prevention/oh.htm. Accessed September 9, 2009.

2. General Accounting Office. Oral health: Dental disease is a chronic problem among low-income populations. Washington, DC: Report to Congressional Requestors; 2000.

3. National Institute of Dental and Craniofacial Research, National Institute of Health, U.S. Public Health Service, Department of Health and Human Services. The invisible barrier: Literacy and its relationship with oral health. A report of a workgroup sponsored by the national institute of dental and craniofacial research, national institute of health, U.S. public health service, department of health and human services. J Public Health Dent 2005 Summer; 65:174-82.

4. Ross LA, Frier BM, Kelnar CJ, Deary IJ. Child and parental mental ability and glycaemic control in children with type 1 diabetes. Diabet Med 2001;18:364-9.

5. DeWalt DA, Dilling MH, Rosenthal MS, Pignone MP. Low parental literacy is associated with worse asthma care measures in children. Ambul Pediatr 2007;7:25-31.

6. Kutner M, Greenburg E, Jin Y, Paulsen C. The health literacy of America's adults: Results from the 2003 national assessment of adult literacy (NCES 2006-483). U.S.Department of Education. Washington, DC: National Center for Education; 2006.

7. Rudd RE. Health literacy skills of U.S. adults. Am J Health Behav 2007 Sep-Oct;31 Suppl 1:S8-18.

8. Yin HS, Johnson M, Mendelsohn AL, Abrams MA, Sanders LM, Dreyer BP. The health literacy of parents in the United States: a nationally representative study. Pediatrics 2009;124 Supple 3:S289-98.

9. Education Portal. National Right to Read Foundation. Available at: http://educationportal.com/articles/Grim_Illiteracy_Statistics_Indicate_Americans_Have_a_Reading_Problem.html. Accessed September 9, 2009.

10. US Department of Health and Human Services. Healthy people 2010. 2nd ed. Washington, DC: US Government Printing Office;2000.

11. Institute of Medicine. Health literacy: A prescription to end confusion. In: Washington, DC: National Academies Press; 2004.

12. ADA. ADA House passes resolutions on oral health literacy. Available at: http://www.ada.org.libproxy.lib.unc.edu/prof/resources/pubs/adanews/adanewsarticle. asp?articleid=2236. Accessed September 9, 2009.

13. Ad Hoc Committee on Health Literacy for the Council on Scientific Affairs, American Medical Association. Health literacy: Report of the council on scientific affairs. JAMA 1999;281:552-7. 
14. US Department of Health and Human Services. Oral health in america: A report of the surgeon general. Rockville, MD: US Department of Health and Human Service, National Institute of Dental and Craniofacial Research;2000.

14. Jackson R. Parental health literacy and children's dental health: Implications for the future. Pediatr Dent 2006;28:72-5.

16. Dewalt DA, Berkman ND, Sheridan S, Lohr KN, Pignone MP. Literacy and health outcomes: A systematic review of the literature. J Gen Intern Med 2004;19:1228-39.

17. Yin HS, Forbis SG, Dreyer BP. Health literacy and pediatric health. Curr Probl Pediatr Adolesc Health Care 2007;37:258-86.

18. Lee JY, Rozier RG, Lee SY, Bender D, Ruiz RE. Development of a word recognition instrument to test health literacy in dentistry: The REALD-30--a brief communication. J Public Health Dent 2007;67:94-8.

19. DeWalt DA, Hink A. Health literacy and child health outcomes: a systematic review of the literature. Pediatrics 2009;124: Supple 3:S265-74.

20. Ferris TG, Dougherty D, Blumenthal D, Perrin JM. A report card on quality improvement for children's health care. Pediatrics 2001;107:143-55.

21. Zarcadoolas C, Pleasant A, Greer DS. Understanding health literacy: An expanded model. Health Promot Int 2005;20:195-203.

22. Sanders LM, Thompson VT, Wilkinson JD. Caregiver health literacy and the use of child health services. Pediatrics 2007;119:86-92.

23. Shick EA, Lee JY, Rozier RG. Determinants of dental referral practices among WICnutritionists in North Carolina. J Public Health Dent 2005;65:196-202.

24. Douglass JM, Tinanoff N, Tang JM, Altman DS. Dental caries patterns and oral health behaviors in Arizona infants and toddlers. Community Dent Oral Epidemiol 2001;29:14-22.

25. NIDCR Data Resource Center. Oral health questions included in National Oral Health Surveys. Available at: http://drc.hhs.gov.libproxy.lib.unc.edu/surveyq/index.htm. Accessed September 9, 2009.

26. Poulsen S, Horowitz HS. An evaluation of a hierarchical method of describing the pattern of dental caries attack. Community Dent Oral Epidemiol 1974;2:7-11.

27. Wong MC, Schwarz E, Lo EC. Patterns of dental caries severity in chinese kindergarten children. Community Dent Oral Epidemiol 1997;25:343-7.

28. Milton, S. A sample size formula for multiple regression studies. Public Opin Q 1986 ;50:112-118.

29. Moon RY, Cheng TL, Patel KM, Baumhaft K, Scheidt PC. Parental literacy level and understanding of medical information. Pediatrics. 1998;102:e25.

30. Sanders LM, Thompson VT, Wilkinson JD. Caregiver health literacy and the use of child health services. Pediatrics. 2007; 119:e86-92. 